\title{
O complexo industrial da saúde e a necessidade de um enfoque dinâmico na economia da saúde
}

\author{
The health industrial complex and the need \\ of a dynamic approach on health economics
}

Carlos A ugusto Grabois Gadelha 1

1 Departamento de Administração e Planejamento em Saúde, ENSP/Fiocruz. Rua Leopoldo Bulhões 1480,70 andar, $M$ anguinhos, 21041-210, Rio de Janeiro RJ. gadelha@ensp.fiocruz.br
Abstract This article develops an analytical approach towards the study of health industrial complex, comprising the set of productive activities on health and their interdependencies, according to a perspective of political economics and innovation. The capitalist enterprising logic penetrates all the productive segments, involving as well the industries which were al ready traditionally working on these bases, as segments having organization forms on which it was possible to verify the acquaintanceship of enterprising logic with others that were moved away from them, as vaccine production and biological products, phyto-derived and health care services. The article analyzes the interaction between the health system and the economical-industrial system, explaining how it has been succeeding a dichotomy on the relation between both of them, which is expressed by the deterioration of the innovation potential of the country and on a growing and worrying external vulnerability of health politics. It is suggested that the traditional neoclassical approach of health economics is not sufficient to attend health industrial complex, due to the intensity of the process of structural change, and the need of a theoretical al ternati ve approach incorporating the dynamics of economic and institutional transformation, of accumulation and innovation.

Key words $\mathrm{H}$ ealth industrial complex, M edical-industrial complex, $\mathrm{H}$ ealth economics, $\mathrm{H}$ ealth innovation system, $\mathrm{H}$ ealth industries
Resumo 0 artigo desenvolve um enfoque analítico vol tado para o estudo do complexo industrial da saúde, englobando o conjunto das atividades produtivas e suas relações de interdepen dência, segundo uma perspectiva de economia política e da inovação. A lógica empresarial capitalista penetra em todos os segmentos produtivos, envolvendo tanto as indústrias que já operavam tradicionalmente nessas bases quanto segmentos que possuíam formas de organização em que era possível verificar a convivência de lógi cas empresariais com outras que dela se afastavam, como a produção de vacinas e produtos biológicos, fitoderivados ea prestação de serviços de saúde. 0 artigo analisa a interação entre o sistema de saúde e o sistema econômico-industrial, mostrando como tem havido uma dicotomia na relação entreambos, que se exprime na deterioração do potencial de inovação do país e numa crescente e preocu pante vulnerabilidade externa da política de saúde. Sugere-se que o enfoque neoclássico tradicional da economia da saúdeé insuficiente para tratar do complexo industrial da saúde, dada a intensidade do processo de mudança estrutural, e a necessidade de um enfoque teórico al ternativo que incorpore a dinâmica de transformação econômica e institucional, de acumulação e de inovação.

Palavras-chave Complexo industrial da saúde, Complexo médico-industrial, Economia da saúde, Inovação em saúde, Indústrias da saúde 
(...) normalmente se vê o problema de como o capitalismo administra as estruturas existentes, enquanto o relevante é saber como ele as cria e as destrói (Schumpeter, 1985).

\section{Apresentação}

Este artigo pretende analisar alguns dos principais traços do desenvolvimento recente do complexo industrial da saúde no Brasil emostrar que sua análise requer um enfoque dinâmico de economia al ternativo ao paradigma neoclássico dominante. Para tanto, a argumentação é desenvolvida em três tópicos distintos. No primeiro, procura-se desenvolver uma visão conceitual sobre o complexo industrial da saúde e del imitar os segmentos produtivos que engl oba e suas relações de interdependência, mostrando sua evolução recente no Brasil e a dicotomia entre a produção de serviços e o desenvolvimento das indústrias da saúde. No segundo, considerando que a dinâmica de inovação constitui o fator central para a análise do complexo, procura-se indicar, sinteticamente, caminhos teóricos alternativos ao dominante na economia - e na economia da saúde, em particular - , que buscam compreender a dinâmica de transformação econômica e institucional e não apenas os processos de al ocação de recursos escassos. Por fim, o último tópico apresenta um comentário final, indican do a necessidade de compatibilização analítica e normativa en tre a lógica econômica da inovação e desenvolvimento e a lógica sanitária.

\section{0 complexo industrial da saúde}

O espaço econômico e institucional que envolve o setor saúde tem passado por profundas transformações no Brasil, seguindo, tardiamente, a tendência dos países desenvolvidos, se bem que em condições históricas e institucionais - e, portanto, estruturais - bastanteespecíficas. A lógica empresarial capitalista penetra de forma arrebatadora todos os segmentos produtivos, envolvendo tanto as indústrias que já operavam tradicionalmente nessas bases - como a farmacêutica e de equipamentos médicos - quanto segmentos produti vos que possuíam formas de organização em que era possível verificar a convivência de lógicas empresariais com outras que dela se afastavam, como a produção de vacinas e outros produtos biológicos, fitoderivados e a prestação de serviços de saúde.

É verdade que o processo de penetração do capital e empresariamento da área de saúde e de constituição de um complexo econômico movido pela lógica de mercado não é novo, já tendo sido identificado por Cordeiro (1980) há mais de 20 anos, quando sugeriu a constituição de um complexo médico-industrial, envolvendo a formação profissional, as indústrias e a prestação de serviços médi cos, focalizando, particularmente, o processo de produção e de consumo de medicamentos. $M$ ais recentemente, essa perspectiva foi retomada por diversos autores, podendo-se citar - livro organizado por Negri e Giovanni (2001), cujos trabalhos abordam tanto uma visão geral do processo de mercantilização da saúde, subseqüente ao período de capitalização (Braga \& Silva, 2001), quanto o estudo dos setores produtores de bens e serviços que fazem parte do complexo, al ém de outros artigos ou trabal hos que procuram tratar das indústrias da saúde e/ou do sistema de inovação em saúde, de acordo com uma perspectiva econômica (Albuquerque \& Cassiolato, 2000; Gadel ha et al., 2002; Temporão, 2002; e Gadelha, 2002).

Com o movimento recente de terceira revolução tecnológica e de globalização, acompanhado, no nível das relações de poder, pela clara hegemonia do sistema capitalista no mundo e pela onda de reformas do Estado, que incidiram de forma marcante no setor saúde, esse processo tornou-se um movimento avassalador em todo o planeta - à exceção dos países e regiões que foram completamente alijados do sistema econômico mundial, com o exemplo dramático da África - , sendo, aparentemente, irreversível, ao menos nos marcos do sistema político e econômico atual. $M$ esmo nas atividades que preservaram sua natureza pública ou estatal, as relações de contratualização e de constituição de quasimercados, além de um conjunto de inovações organizacionais (criação de organismos públicos não-estatais, terceirização, organização de cooperativas de trabal hadores, etc.), passam a pressionar os agentes para segui rem lógicas de obtenção de competitividade e de eficiência econômica em suas atividades (Ribeiro et al., 2001) - a despeito de, no Brasil, o processo ser incremental (Costa et al., 2000) - aproximando progressivamente essas organizações de 
lógicas tipicamente empresariais.

Em síntese, tanto os espaços privados quanto os públicos estão passando por um processo de transformação no modelo de gestão e organização da produção de bens e serviços em saú de na direção de um padrão empresarial, inclusive nos casos em que o objetivo do lucro não se coloca como finalidade primordial, sendo substituído por metas alternativas de desempenho (referidas, por exemplo, à produção, qualidade, custos e compromissos de atendimento de populações ou clientelas específicas). Deve-se observar, no entanto, que, mesmo considerando o caráter assimétrico e gerador de desigualdade no nível das relações entre indivíduos, segmentos sociais, espaços subnacionais, nacionais e regionais, este movimento não pode ser visto como uma "anomalia" específica ao setor saúde, mas sim como um processo muito mais geral decorrente da expansão do sistema capital ista.

Essa ten dência de disseminação global e setorial da lógica capitalista foi há muito identificada por grandes pensadores do final do século 19 e da primeira metade do século 20, como M arx (1983), Schumpeter (1985) e W eber (1993, por exemplo), em suas análises do impulso expansivo do capitalismo mediante, respectivamente, o processo de "desenvolvimento das forças produtivas", de "destruição criativa" - ambos movidos pela concorrência empresarial - e de disseminação da "racionalidade ou espírito capital ista." Sob perspectivas diferenciadas, esses autores evidenciaram o movimento contraditório do capitalismo, associado, de um lado, ao seu caráter progressista em termos de geração de riqueza e da institucionalização das relações de poder, e, de outro lado, à tendência de autonomização da dinâmica empresarial e institucional, descolando-se de finalidades diretamente associadas às necessi dades humanas, sejam elas expressas no consumo e utilidade dos bens e serviços, na busca do bem-estar social, na igualdade ou mesmo numa vontade geral idealizada.

N essa direção, o setor saúde constitui, simultaneamente, um espaço importante de inovação e de acumulação de capital, gerando oportunidades de investimento, renda e emprego - ou seja, constitui um locus essencial de desenvolvimento econômico - quanto uma área que requer uma forte presença do Estado e da sociedade para compensar as forças de geração de assimetrias e de desi gual dade as- sociadas à operação de estratégias empresariais e de mercado. Pode-se afirmar que o novo contexto econômico, tecnológico e político representa uma mudança qual itativa na dinâmica do complexo e no seu padrão diferenciado de organização nos espaços nacionais, requerendo também um esforço analítico para se repensarem as tendências vigentes e o papel do Estado e das políticas públicas.

Seguindo essa perspectiva analítica, a delimitação do complexo industrial da saúde constitui, mais do que uma simples sel eção de setores de atividade a partir de sua linha de produto (como medicamentos e equipamentos médicos) ou da propriedade do capital (segmento privado), um corte analítico que representa um ol har diferenciado frente à forma tradicional de abordar o setor saúde, representando uma percepção da área como um conjunto interligado de produção de bens e serviços em saúde que se movem no contexto da dinâmica capitalista. De um lado, possui fortes especificidades frente a qualquer outro complexo de atividades; de outro, compartiIha a característica geral de se inserir como um conjunto de atividades capitalistas, seja diretamente via relações típicas de mercado ou indiretamente pela inserção no marco do padrão de regulação vigente ( no sentido amplo do termo - Boyer, 1988) nos distintos países que fazem parte do sistema atual.

Com esse ol har, o complexo industrial da saúde pode ser delimitado como um complexo econômico, efetuando-se um corte, analítico e com um grau inescapável de arbitrariedade, a partir de um conjunto selecionado de atividades produtivas que mantêm relações intersetoriais de compra e venda de bens e serviços ( sendo captadas, por exemplo, nas matrizes de insumo-produto nas contas nacionais) e/ou de conhecimentos e tecnologias (Erber, 1992). Além disso, seguindo uma tradição de economia política, que considera o próprio mercado um espaço institucionalmente construído, esse conjunto particular de setores econômicos está inserido num contexto político e institucional bastante particular dado pelas especificidades da área da saúde. Como decorrência da convergência de setores de atividades, empresas, instituições públicas, privadas e da sociedade civil para um determinado espaço econômico de geração de investimento, consumo, inovação, renda e emprego, conforma-se um complexo industrial (no sentido de atividades que seguem 
Figura 1

Complexo industrial da saúde - caracterização geral

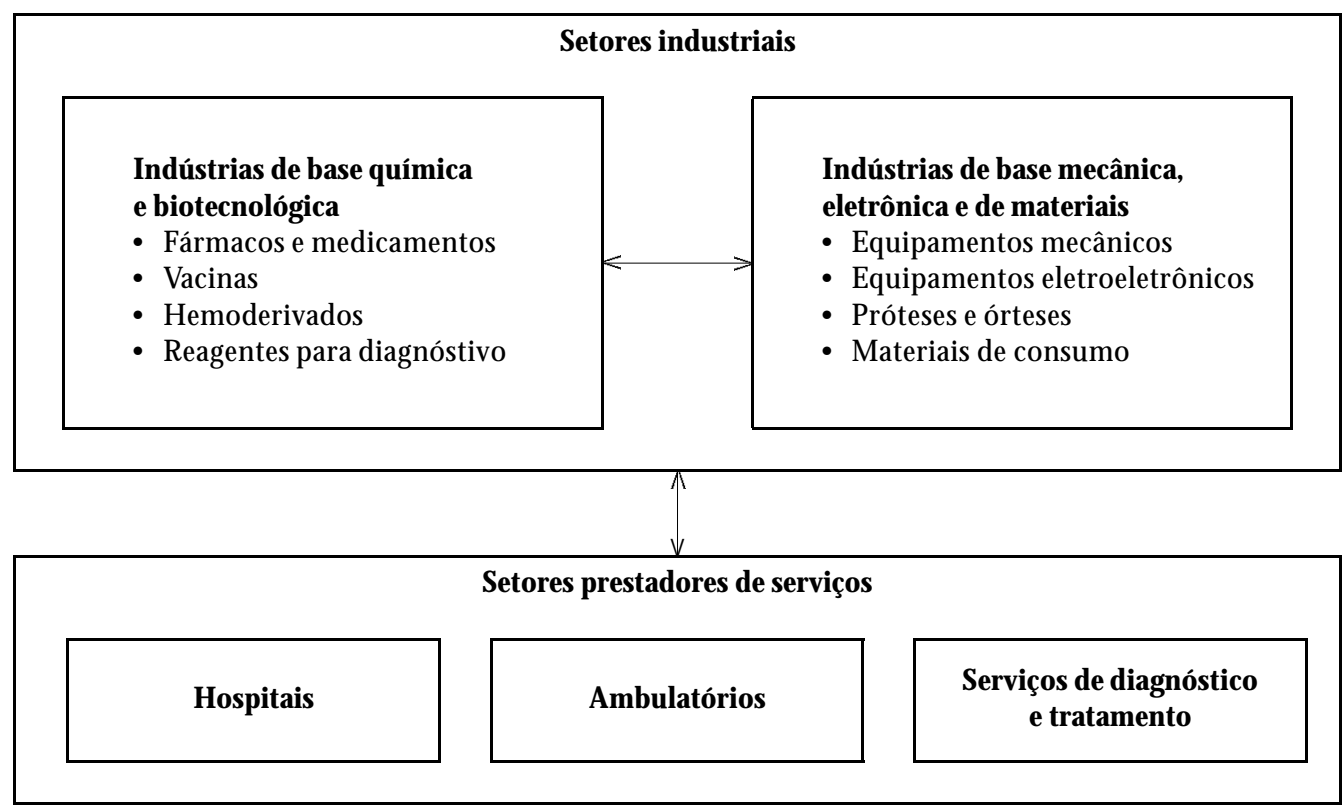

o padrão industrial mesmo que formalmente pertençam ao setor de serviços) como uma base concreta e empírica para a delimitação de um locus analítico e normativo determinado.

A figura 1 permite uma visão geral do complexo industrial da saúde, envolvendo um conjunto de indústrias que produzem bens de consumo e equipamentos especial izados para a área e um conjunto de organizações prestadoras de serviços em saúde que são as consumidoras dos produtos manufaturados pelo primeiro grupo, caracterizando uma clara relação de interdependência setorial .

Do ponto de vista material, e em consonância com a base de conhecimento e tecnológica, é possível formar três grandes grupos de atividade. 0 primeiro congrega as indústrias de base química e biotecnológica, envolvendo as indústrias farmacêutica, de vacinas, hemoderivados e reagentes para diagnóstico. Como o setor de medicamentos constitui o grande mercado desse grupo, sendo liderado por um conjunto de grandes empresas, altamente intensivas em tecnologia eque dominam o mercado mundial, há uma tendência de "transbordamento" da indústria farmacêutica, ampliando suas fronteiras para englobar os demais segmentos como já está ocorrendo na área de vacinas (Gadelha \& Temporão, 1999).

O segundo grupo congrega um conjunto bastante díspar de atividades de base física, mecânica, eletrônica e de materiais, envolvendo as indústrias de equipamentos e instrumentos mecânicos e el etrônicos, órteses e próteses e materiais de consumo em geral. N este grupo, cabe destacar o papel da indústria de equipamentos, tanto pelo seu potencial de inovação - incorpora fortemente os avanços no paradigma microeletrônico quanto pelo seu impacto nos serviços, representando uma fonte permanente de mudanças nas práticas assistenciais, trazendo permanentemente para o debate a tensão entre a lógica da indústria e a sanitária.

0 terceiro grupo de atividades congrega os setores envolvidos com a prestação de serviços de saúde, englobando as unidades hospitalares, ambulatoriais e de serviços de diagnóstico etratamento. Esses setores organizam a cadeia de suprimento dos produtos industriais em saúde, articulando o consumo por parte dos cidadãos no espaço público e privado. De um lado, na taxonomia de organização 


\section{Figura 2}

Complexo político e institucional do complexo da saúde

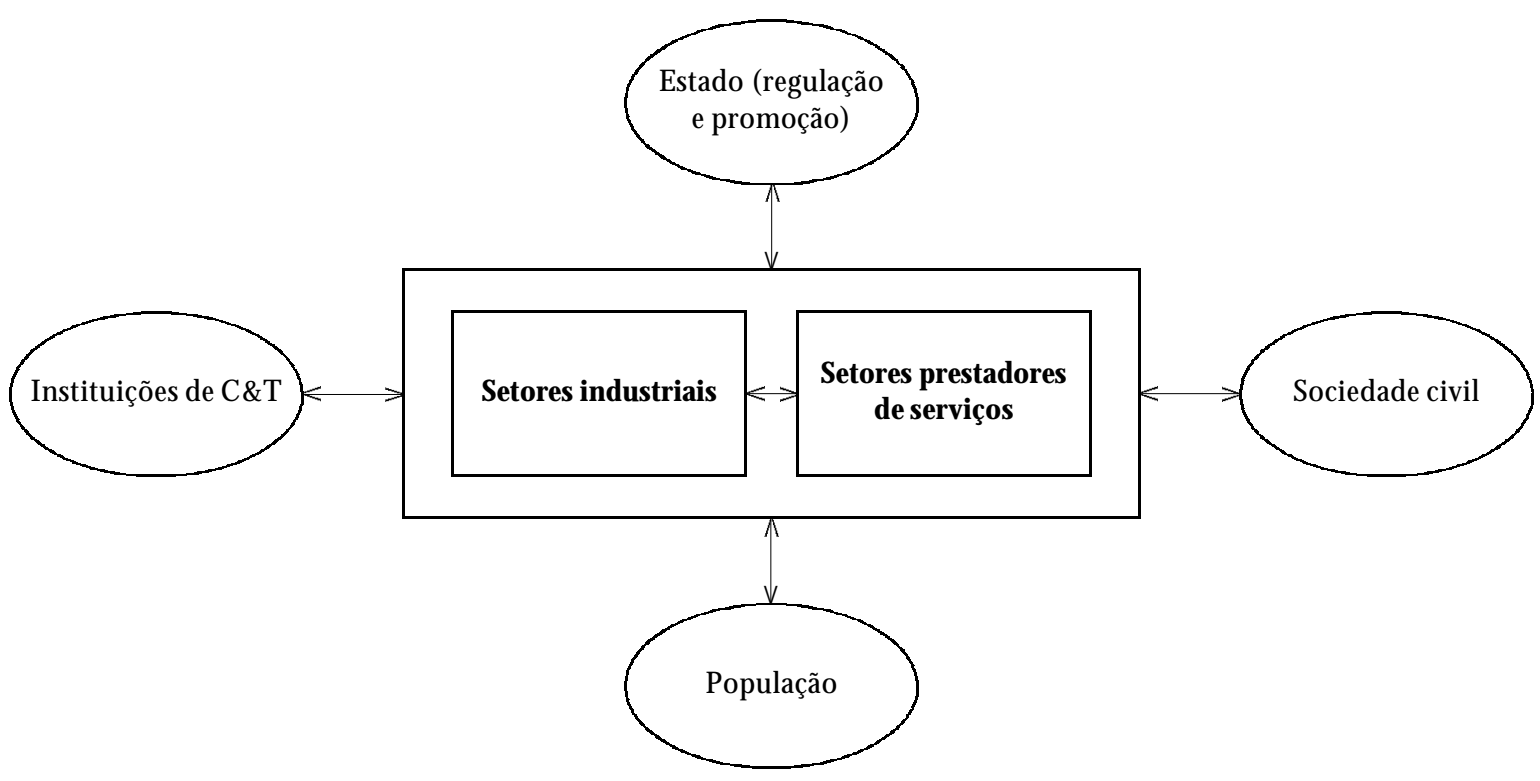


ção e às atividades regulatórias que desempenha, numa forte interação com a sociedade civil organizada.

Com base nessa delimitação analítica e descritiva, pode-se afirmar que a dinâmica do complexo industrial da saúde deve ser apreendida com base em duas dimensões interligadas que refletem um certo modo de regulação ou padrão de desenvolvimento capitalista (Boyer, 1988) em âmbito setorial.

$\mathrm{N}$ a primeira dimensão, os segmentos que fazem parte da área, ao compartilharem um alto grau de inovação, apresentam um elevado dinamismo em termos de taxa de crescimento e de competiti vidade (Gelijns \& Rosemberg, 1995), considerando a interação entre inovação e desenvolvimento econômico (Dosi et al., 1994). Expressando essa característica, os setores da saúde, invariavelmente, estão entre os que recebem maior estímulo governamental à competitividade e à inovação, sendo veículos importantes dos novos paradigmas tecnológicos que estão por trás da revolução tecnológica em curso, liderada pelas tecnologias de informação, englobando a biotecnologia (Castells, 1999).

N essa vertente, o Estado possui um papel destacado, sendo possível verificar, no âmbito dos países desenvolvidos, um conjunto de ações convergentes para apoiar a competitividade das indústrias e as empresas do comple$x o$, envolvendo o financiamento e incentivos às ati vi dades de pesquisa e desenvolvimento $(P \& D)$, política comercial, de compras, propriedade intelectual, estímulo a parcerias entre universidades, hospitais e empresas, a montagem de infra-estruturas de serviços técnicos, entre outras modalidades de intervenção (Rosemberg \& N elson, 1994; N egri \& Giovanni, 2001).

$\mathrm{N}$ a segunda dimensão, a saúde constitui um val or humano associado à própria cidadania, havendo interesses sanitários legítimos voltados para a garantia das condições de saúde, levando a uma ação política e social para o acesso aos bens eserviçose, simultaneamente, para o estabel ecimento de constrangimentos que limitem a ação econômica dos agentes e, em particular, a estratégias empresariais das organizações públicas e privadas. Essas organizações, de um lado, são ben eficiárias da demanda crescente e relativamente inelástica pel os bens e serviços que produzem; de outro, têm a sua flexibilidade de operação e de busca delucratividade ou outro objetivo vinculado ao desempenho fortemente limitadas. Do ponto de vista da política social, essa dimensão da saúde se expressa na preservação dos gastos em saúde, uma vez que, a despeito dos esforços general izados em termos internacionais para a conten ção do gasto público, a partir dos anos 80, a área da saúde tem preservado tanto sua participação nas despesas nacionais financiadas pelo setor público quanto a magnitude da interven ção estatal na regulação e nas ações de assistência e de promoção, mesmo quando ocorreram transformações na forma de ação do Estado no âmbito dos governos que tiveram a marca das políticas referidas como neoliberais (Pierson, 1995).

N essa direção, pode-se afirmar que a dimensão econômica, vinculada ao processo de inovação e de acumulação, e a dimensão sociossanitária apresentam, sob uma perspectiva, um trade- off que contrapõe o interesse de eficiência econômica dos agentes e os interesses da po pulação. Sob outra perspectiva, a segunda dimensão representa fonte de deman$\mathrm{da}$, de financiamento, de prioridade às atividades de $P \& D$, entre outras condições sistêmicas de competitividade que incidem favoravel mente na lucratividade e/ou no desempenho dos agentes públicos e privados e, portanto, na renda, no investimento e no desenvolvimento das economias nacionais. A "arte" política rel acionada a essas tensões e sinergias entre as duas dimensões relaciona-se à administração deste trade- off por parte dos Estados nacionais. Em alguns casos, como nos países escandinavos, conforma-se uma situação na qual está se consolidando um complexo industrial de bem-estar, articulando os interesses empresariais e de saú de em torno de estratégias de inovação e de competitividade das indústrias e dos serviços de saúde, o que tem levado alguns autores a identificarem a área social como uma alavanca potencial de inovação e desenvolvimento das economias nacionais (Lundvall, 1988).

No Brasil, a situação vigente se caracteriza pela desarticulação dessas duas dimensões, havendo um descolamento entre a forma de operação e organização do sistema de saúde e a dinâmica dos setores de atividade e sobretudo das inovações (Gadel ha et al., 2002).

Com relação ao sistema de saúde, da segunda metade dos anos 80 até o presente, assistiu-se a um processo de inovação organizacional sem precedentes na história das políticas sociais no Brasil, envolvendo desde a con- 
cepção dos princípios do SU S no texto constitucional até uma total reestruturação na forma de organização do governo federal (eliminação da distinção entre trabal hadores vinculados à previdência social e os demais segmentos da população, extinção do Inamps, reorganização do M inistério da Saúde, etc.) e de sua relação com os Estados e municípios e com a sociedade civil.

N esse processo, o Estado brasileiro se consolidou como um agente central e com presença penetrante em todo o território nacional na área da saúde, possuindo um alto poder de regulação e de promoção das ações em saúde. Esse movimento ocorreu, de certa forma, na contramão da evolução do aparelho de Estado no Brasil, com o governo federal assumindo um papel de promoção, coordenação e normatização, evidenciado pela implementação das normas de assistência à saúde, pela criação de agências reguladoras ( A gência $\mathrm{Na-}$ cional de Vigilância Sanitária e A gência $\mathrm{Na}$ cional de Saúde Suplementar) e pela montagem de todo um aparato institucional de planejamento e programação entre os diferentes níveis da Federação, vinculado ao estabelecimento de fluxos de recursos da União para os Estados e municípios (Cordeiro, 2001; e Levcovitz et al., 2001).

Com relação à dinâmica econômica dos setores de atividade, observa-se, primeiramente, a brutal expansão do sistema assistencial na segunda metade do século 20 , havendo um crescimento exponencial, especialmente a partir de 1960, evidenciado, entre muitos outros indicadores e informações, pelo incremento no número de leitos para internação e de consultas médicas e pelo número de estabelecimentos ambulatoriais e hospitalares (N oronha \& Levcovitz, 1994). N os anos 90, a expansão desse setor de ati vidade tem continuidade, podendo-se destacar a expansão de $22 \%$ no número de estabelecimentos públicos entre 1992 e 1999 - simultaneamente a uma reorganização profunda na forma de organização da rede, finalizando a década com $92 \%$ das unidades sob gestão municipal - ea significativa taxa de crescimento no emprego nos estabel ecimentos públicos e privados, atingindo, respectivamente, $36 \%$ e $26,5 \%$ mesmo período considerado (Costa e Barros Silva, 2002). Observe-se que os dados in dicam um dinamismo dificilmente encontrado em outro setor de atividade econômica do país, no contexto de uma década em que o nível de de- semprego atingiu um patamar em torno de 10 milhões de pessoas.

Além desses indicadores associados à rede hospitalar e ambulatorial, também se observa um conjunto significativo de ações vinculadas ao SUS que incidem de forma importante na dinâmica econômica do complexo da saúde, com destaque para os programas de agentes comunitários de saúde e de saúde da família. Estes, de um lado, ao alterarem o modelo assistencial tradicional, constituem um conjunto de serviços substitutivos em relação à demanda da rede hospitalar e ambulatorial existente, mas, de outro lado, podem significar uma pressão para o aumento, mesmo que a taxas diferenciadas, tanto de novos serviços decorrentes do novo model o quanto dos serviços ofertados pelos estabelecimentos de saúde e pela indústria, em decorrência do impacto dos programas na abertura do acesso para segmentos importantes da população que passam a ser progressivamente incorporados ao sistema. Segundo o M inistério da Saúde, o número de agentes de saúde subiu de 29 mil para mais de 110 mil no período 19941999, atingindo uma população de 64 milhões de pessoas, enquanto as equipes de saúde da família saíram de um patamar próximo de zero para quase 5.000 equipes no mesmo período, atingindo 17 milhões de pessoas ( M inistério da Saúde, 2000). Certamente, essa expansão e transformação do sistema representam uma nova fonte de demanda para os prestadores públicos e privados e para as indústrias da saúde, que se desdobram na geração de salários, lucros, investimentos, emprego erenda.

Por fim, há uma série de programas mais focalizados que exercem um impacto importante tanto no acesso a bens e serviços essenciais quanto na demanda de amplos segmentos industriais. N essa vertente, destacam-se, entre outros, os programas de assistência farmacêutica e medicamentos genéricos, imunização, controle de endemias, hemoderivados, controle da qualidade do sangue e o REFORSUS. A cada um desses programas está associado um grupo de empresas ou agentes econômicos e segmentos industriais, cujo dinamismo é particularmente afetado, representando fontes potenciais de competitividade.

No campo do sistema privado de saúde, cabe destacar, como um dos fatos mais marcantes no período recente, a conformação de um subsistema (ou mesmo de um sistema paralelo) privado de organização dos serviços de 
saúde que tem apresentado um elevado potencial de crescimento. Esse segmento está calcado, de um lado, na atuação competitiva de empresas operad oras de planos e seguros de saúde, envolvendo modalidades de autogestão, medicina de grupo, cooperativas médicas e seguradoras, e, de outro lado, na atuação regulatória do Estado, mediante a atuação da Agência N acional de Saúde Suplementar (lei 9.656 de 1998), que, de fato, representa uma forma de estruturação de um espaço econômico delimitado, refletindo a consolidação institucional de um novo mercado, agora não mais fragmentado em segmentos e lógicas distintas. Seja qual for a modalidade empresarial, todas as operadoras concorrem entre si em bases semelhantes e adotam um determinado padrão de concorrência e de estratégias competitivas, envolven do a busca de diferenciação de produtos, de clientel as e regiões com distintos graus de abrangência, segmentação e focal ização.

A importância desse mercado é refletida pelas informações de que o sistema privado já atende a aproximadamente 40 milhões de pessoas - ou quase $30 \%$ da população brasileira - , apresentando um faturamento anual da ordem de $\mathrm{R} \$ 16$ bilhões (levantamento junto à AN S e Bahia, 2001), o que aponta para uma série de questões (os mencionados trade-offs) advindas da tensão entre os princípios da conformação do sistema brasileiro de saúdee o desenvolvimento empresarial no nível microeconômico.

Com relação à dinâmica dos setores industriais, evidencia-se que, conforme apurado e desenvolvido em um projeto recente de pesquisa (Gadelha, 2002), sob uma perspectiva, o período recente se caracterizou por uma expansão significativa da atividade produtiva em segmentos importantes como medicamentos, equipamentos, materiais médicos, vacinas e soros. Conforme levantamento efetuado junto às associações empresariais, em documentos oficiais, na literatura e em entrevistas com informantes-chave, em todos esses segmentos o dinamismo da demanda pública advinda da expansão da produção e da capacidade da rede de serviços se mostrou uma das principais fontes de competitividade e de crescimento, se adicionando aos incentivos de curto prazo do ambiente regulatório dos anos 90, relacionado, entre outros aspectos, à abertura comercial para a importação de insumos e produtos intermediários e à liberal ização de preços, notadamente na área de medicamentos.

Sob outra perspectiva, a década de 1990 representou um período de deterioração acentuada da competitividade da indústria nacional, decorrente da fragilidade empresarial, do processo de abertura comercial e de entrada passiva no processo de globalização em saúde, tod os esses fatores associados à perda de capacitação tecnológica e do potencial deinovação em saúde. Como mencionado, as inovações constituem o elemento crítico da competitividade nas in dústrias da saúde, considerando que estas são al tamente intensi vas nos novos paradigmas de informação e comunicação. A ausência de uma política industrial para os setores da saúde al iada a uma política macroeconômica que envolveu uma liberalização comercial abrupta, a valorização da taxa cambial (até 1999) e taxas de juros extremamente elevadas inviabilizaram estratégias de longo prazo das empresas, minando a capacidade de inovação e, portanto, a base competitiva da indústria. Com isso, pode-se dizer que a divergência entre 0 ambiente macroeconômico e a expansão do sistema de saúde acabou restringindo uma interação que poderia ter se mostrado bastante promissora entre a expansão do sistema de saúde e o dinamismo dos segmentos industriais. D efato, o ocorrido na década reflete uma tensão, não resolvida até o presente, entre a lógica da saúde e a lógica econômica, sempre tratada como uma relação viciosa e com interesses opostos e incompatíveis.

Os dados de comércio exterior revelam o grau de deterioração da capacidade competitiva das indústrias de saúde e como a situação constitui, de fato, um problema crítico para a política de saúde e, num âmbito mais geral, para a política nacional de desenvolvimento. A tabela 1 procura fazer um balanço do comércio exterior do complexo industrial da saúde no período posterior a 1997, quando foi adotada a N omenclatura Comum do M ercosul (NCM) em substituição à N omenclatura Brasileira de M ercadorias (N BM) na classificação das relações comerciais do país.

Para a análise desenvolvida, cabe destacar que a situação de depen dência comercial em saúde é generalizada. Todos os segmentos produtivos, sem exceção, apresentam um déficit comercial significativo em todos os anos do período 1997-2001. Observe-se que, no período, houve uma forte desvalorização com a 
Tabela 1

Evolução do comércio exterior - Complexo da Saúde. Valores em U SD FOB correntes.

\begin{tabular}{|c|c|c|c|c|c|}
\hline & 1997 & 1998 & 1999 & 2000 & 2001 \\
\hline \multicolumn{6}{|l|}{ Exportação } \\
\hline Equip./M ateriais & 159.929 .818 & 165.886 .908 & 171.245 .016 & 190.015 .316 & 183.758 .633 \\
\hline Ap. ñ eletrônicos & 2.072 .331 & 1.595 .264 & 821.989 & 479.540 & 112.076 \\
\hline Ap. eletrônicos & 52.188 .121 & 56.023 .619 & 50.543 .715 & 57.153 .334 & 56.214 .104 \\
\hline Próteses/órteses & 17.398 .418 & 20.258 .129 & 25.730 .306 & 30.423 .707 & 29.607 .055 \\
\hline Mat. consumo & 88.270 .948 & 88.009 .896 & 94.149 .006 & 101.958 .735 & 97.825 .398 \\
\hline Vacinas & 244.005 & 584.390 & 273.650 & 147.676 & 2.664 .299 \\
\hline Reag. Diagnóstico & 2.348 .682 & 2.402 .280 & 3.677 .260 & 2.913 .419 & 1.454 .531 \\
\hline Soros etoxinas & 284.054 & 507.399 & 439.088 & 352.142 & 461.203 \\
\hline Hemoderivados & 576.565 & 887.671 & 655.276 & 777.712 & 1.959 .307 \\
\hline M edicamentos & 111.139.117 & 152.099 .786 & 186.090 .130 & 165.905 .047 & 179.162 .943 \\
\hline Fármacos & 246.245 .730 & 278.127.614 & 228.397.275 & 189.150 .063 & 183.493 .863 \\
\hline Total & 520.767 .971 & 600.496 .048 & 590.777 .695 & 549.261 .375 & 552.954 .779 \\
\hline \multicolumn{6}{|l|}{ Importação } \\
\hline Equip./ M ateriais & 1.027 .258 .105 & 1.090 .367 .572 & 871.993 .031 & 903.816 .359 & 1.054 .382 .119 \\
\hline Ap. ñ eletrônicos & 15.162 .437 & 13.665 .430 & 11.720 .137 & 11.740 .508 & 11.490 .388 \\
\hline Ap. eletrônicos & 721.118 .288 & 766.091 .911 & 542.374 .663 & 546.217 .289 & 713.287 .332 \\
\hline Próteses/órteses & 65.638 .918 & 70.576 .371 & 69.588 .168 & 86.680 .016 & 82.711 .274 \\
\hline Mat. consumo & 225.338 .462 & 240.033 .860 & 248.310 .063 & 259.178 .546 & 246.893 .125 \\
\hline Vacinas & 74.015 .346 & 69.059 .563 & 125.454 .174 & 119.585 .393 & 123.783 .855 \\
\hline Reag. Diagnóstico & 126.472 .712 & 131.310 .221 & 143.187.312 & 131.272 .623 & 127.180 .701 \\
\hline Sorosetoxinas & 11.736 .451 & 13.788 .855 & 13.969 .626 & 27.126.382 & 38.368 .321 \\
\hline H emoderivados & 71.665 .031 & 92.943 .661 & 138.913.708 & 150.190 .133 & 200.671 .120 \\
\hline M edicamentos & 784.589 .413 & 935.797.492 & 1.115 .894 .609 & 1.013 .434 .883 & 1.039 .063 .849 \\
\hline Fármacos & 1.192 .878 .841 & 1.528 .654 .819 & 1.473 .605 .785 & 1.333 .989 .647 & 1.432 .882 .794 \\
\hline Total & 3.288.615.899 & 3.861 .922 .183 & 3.883.018.245 & 3.679 .415 .420 & 4.016 .332 .759 \\
\hline \multicolumn{6}{|l|}{ Saldo Comercial } \\
\hline Equip./ $M$ ateriais & -867.328 .287 & -924.480 .664 & -700.748 .015 & -713.801 .043 & -870.574 .258 \\
\hline Ap. ñ eletrônicos & -13.090 .106 & -12.070 .166 & -10.898 .148 & -11.260 .968 & -11.378 .312 \\
\hline Ap. eletrônicos & -668.930 .167 & -710.068 .292 & -491.830 .948 & -489.063 .955 & -657.024 .000 \\
\hline Próteses/órteses & -48.240 .500 & -50.318 .242 & -43.857 .862 & -56.256 .309 & -53.104 .219 \\
\hline Mat. consumo & -137.067 .514 & -152.023 .964 & -154.161 .057 & -157.219 .811 & -149.067 .727 \\
\hline Vacinas & -73.771 .341 & -68.475 .173 & -125.180 .524 & -119.437 .717 & -121.119 .556 \\
\hline Reag. Diagnóstico & -124.124 .030 & -128.907 .941 & -139.510 .052 & -128.359 .204 & -125.726 .170 \\
\hline Outros (soros etoxinas) & -11.452 .397 & -13.281 .456 & -13.530 .538 & -26.774 .240 & -37.907 .118 \\
\hline Hemoderivados & -71.088 .466 & -92.055 .990 & -138.258 .432 & -149.412 .421 & -198.711 .813 \\
\hline M edicamentos & -673.450 .296 & -783.697 .706 & -929.804 .479 & -847.529 .836 & -859.900 .906 \\
\hline Fármacos & -946.633 .111 & -1.250 .527 .205 & -1.245 .208 .510 & -1.144 .839 .584 & -1.249 .388 .931 \\
\hline Total & -2.767 .847 .928 & -3.261 .426 .135 & -3.292 .240 .550 & -3.130 .154 .045 & -3.463 .328 .752 \\
\hline
\end{tabular}

Fonte: Elaboração própria a partir de levantamento demandado ao N úcleo de Economia Industrial e da Tecnologia - Instituto de Economia/Unicamp junto à Secex, no âmbito do projeto Complexo da Saúde, integrante do Estudo de Competitividade por Cadeias Integradas - Convênio M DIC/M CT/FECAM P, sob a coordenação geral do prof. Luciano Galvão Coutinho.

mudança do regime cambial em 1999 (de fato, uma "megadesvalorização" de $121 \%$ contra uma inflação acumulada de $24 \%$, segundo apuração do Banco Central e do IPCA/IBGE), cujo impacto somente atenuou o déficit no ano 2000. Em 2001, o valor das importações atinge US $\$ 4$ bilhões, ficando o déficit num patamar deU $\$ 3,5$ bilhões, mesmo num contexto de clara estagnação da economia e, portanto, de demanda contida por importações.
Em termos gerais, a evolução indicada aponta para o caráter estrutural da dependência do país, não se aplicando uma visão meramente alocativa dos fluxos de comércio exterior baseada na evolução dos preços relativos. N essa direção, pode-se afirmar que, em primeiro lugar, a raiz da depen dência de importações reflete a baixa capacitação local em inovação em saúde. Como já mencionado, os segmentos em saúde são de alta tecnologia e a 
inovação constitui a arma competitiva essencial das estratégias empresariais e nacionais. 0 baixo potencial empresarial de inovação em química fina, eletrônica e biotecnologia em saúde leva o país a ser pouco competitivo no complexo da saúde, estando na raiz da dependência de importações de fármacos, equipamentos (sobretudo os el etrôni cos e de maior complexidade), vacinas, reagentes para diagnóstico e hemoderivados.

Em segundo lugar, e de modo relacionado, a situação presente também reflete a inserção passiva do complexo da saúde no movimento de globalização, tendo havido um novo direcionamento dos fluxos comerciais movidos pelas estratégias empresariais de configuração global das grandes empresas multinacionais da saúde. Como decorrência, as exportações brasileiras têm se direcionado para regiões de baixo dinamismo enquanto as importações são crescentemente provenientes de países desenvolvidos ou daqueles países, como a Índia e China, que estão implantando políticas ativas para o desenvolvimento das indústrias da saúde (Gadelha, 2002). O u seja, mesmo nos setores que, em princípio, o país detém capacidade tecnológica e competitiva, como no caso dos medicamentos (etapa de formulação final) , o ambiente global e nacional tem se mostrado desfavorável para 0 atendimento da demanda em saúde pela indústria instalada no país seja de capital majoritariamente nacional ou estrangeiro.

Para se chegar a essa situação, a política de abertura comercial e a (não) política industrial e tecnológica ao longo de toda a década de 1990 mostraram-se desastrosas. A pesar de, em grande parte dos segmentos do complexo, não ser possível comparar com precisão os dados anteriores e posteriores a 1997, em função da mudança referida na classificação das estatísticas nacionais, uma análise dos dados em conjunto com a literatura que trata a evolução dos principais segmentos no período anterior (Furtado \& Souza, 2001; Gadel ha et al., 2002; M agalhães et al., 2002; Q ueiroz. \& Gonzáles, 2001; e Temporão, 2002) mostra que, mesmo sendo a dependência produtiva e tecnológica em saú de uma característica histórica das indústrias baseadas no país, a situação se deteriorou acirradamente nos anos 90, apresentando um crescimento exponencial do déficit no complexo como um todo: enquanto no início da década passada o déficit dos principais segmentos se situava no pa- tamar US\$700 milhões, no final da década passou a se situar acima de U $\$ 3,0$ bilhões ( ou seja, algo entre $500 \%$ e $600 \%$ de incremento!), caracterizando uma situação de dessubstituição de importações ou mesmo de desindustrialização em saúde.

Essa situação também reflete a desarticulação entre a política de saúde e uma política para o desenvolvimento das indústrias do setor. Com exceção da área de vacinas - cujas importações de matérias-primas (bulk) para utilização no programa de imunização estão associadas a um processo (ainda incerto) de absorção de tecnologias de fronteira pelos produtores locais (Bio-M anguinhos/Fiocruz e Butantã) - , nos demais segmentos se assistiu a uma situação em que políticas bem-sucedidas de saú de se refletiam em maior dependência de importações. Com isto, e como um resultado da forma tradicional em que o complexo de saúde vem sendo trabalhado na teoria e na prática - desconsiderando a lógica econômica capital ista subjacente - , o sucesso de algumas políticas implementadas (investimentos na rede hospitalar e ambulatorial, acesso a medicamentos e a hemoderivados, exigência de testes para controle da qualidade das transfusões sangüíneas e o próprio aumento da cobertura das ações assistenciais, entre outros exemplos) tiveram, como contrapartida, um aumento da vulnerabilidade do país e da política de saúde, em particular, chegando-se a uma situação em que o câmbio e as restrições externas colocam em risco o próprio desenvolvimento ea reestruturação em curso no sistema nacional de saúde.

Em síntese, os resultados observados na década refletem tanto uma conjunção perversa da política macroeconômica, industrial, de comércio exterior e tecnológica quanto a dissociação entre as duas principais partes do complexo industrial da saúde - a prestação dos serviços e a produção industrial -, vulnerabilizando 0 avanço da política nacional de saúde.

\section{A necessidade de um paradigma teórico alternativo}

Como desenvolvido no tópico anterior, o complexo industrial da saúde vem passando, no Brasil, por um típico processo de mutação industrial e do ambiente institucional, envolvendo profundas transformações na estrutura 
produtiva, nas estratégias das organizações públicas e privadas, nas formas de atuação do Estado e na organização dos serviços de saúde. O bserva-se um nítido processo de destruição criativa de corte schumpeteriano (Schumpeter, 1985), que resulta em oportunidades edesafios para o desenvolvimento do complexo no país. N esse contexto, não se trata de analisar os movimentos al ocativos em estruturas estáticas compostas por agentes representativos maximizadores, mas sim de analisar como elas se transformam a partir das forças endógenas da inovação, conforme indica o trecho citado na epígrafe.

$N$ essa perspectiva, o enfoque neoclássico tradicional de economia, largamente predominante na análise econômica atual, inclusive no campo da saúde - o que parece estranho, considerando a tradição teórica, de corte político e institucional, em saúde coletiva - , se mostra inadequado ao se concentrar na alocação de recursos escassos - que, segundo essa corrente, define o próprio objeto da ciência econômica - , focalizando situações estáticas ou de crescimento em condições de equilíbrio. A análiseda evolução e os desafios apresentados pelo complexo industrial da saúde tornam uma necessidade a introdução de um enfoque dinâmico de economia no campo da saúde, que focal ize os processos de desenvolvimento, de acumulação de capital e de inovações, recuperando abordagens de economia política, com destaque para as tradições keynesianas, marxistas e schumpeterianas, hoje incorporadas em escolas importantes de pensamento econômico, em particular a neo-schumpeteriana eregulacionista. Essas abordagens, na visão adotada, permitem retomar a perspectiva estruturalista em bases microfundamentadas, empregando um largo instrumental qualitativo e quantitativo e tendo como seu foco analítico enormativo os processos deinovação, o desenvolvimento em condições de desequilíbrio e o caráter institucional do sistema capitalista e da economia de mercado (N elson \& Winter, 1982; e Dosi et al., 1988, incorporam algumas das referências seminais mais importantes).

Sem ter a pretensão de desenvolver a questão em toda sua complexidade - o objetivo aqui é apontar caminhos teóricos e de pesquisa à luz de necessidades apontadas pelo estudo da dinâmica capitalista e da inovação em saúde-, aprofunda-se a seguir 0 argumento, procurando-se fazer um contraponto com as premissas essenciais do pensamento neoclássico.
Todo o referencial teórico neoclássico é construído com base em duas grandes premissas (Possas, 1997):

a) os agentes se comportam etomam decisões possuindo uma racionalidade substantiva acerca da realidade, no sentido que detêm pleno conhecimento do mundo e dos diversos estados possíveis da natureza, sendo capazes de reduzir a incerteza a cál culos probabilísticose, portanto, de adotar estratégias de maximização de lucros ou de qualquer função-utilidade; b) o equilíbrio constitui a norma, a tendência e o resultado da interação entre os agentes, supondo-se que todos maximizam, que as ineficiências tendem a ser eliminadas e que o mercado, operando em condições naturais elivres de interferências, atinge uma condição alocativa ótima, na qual nenhum agente pode melhorar sem que outro piore sua satisfação pessoal, dada a restrição orçamentária existente.

Os processos de inovação, vitais no campo do complexo da saúde, não se mostram compatíveis com essas duas premissas.

A refutação da hipótese comportamental neoclássica, assentada no princípio de maximização, baseia-se no conceito de racionalidade limitada. A idéia é que, num contexto de inovação e transformação das estruturas, 0 comportamento dos agentes não pode ser reduzido a uma racionalidade que independe de sua história e de sua capacitação em sentido amplo. 0 conceito de racionalidade limitada embute a idéia de que os agentes tomam decisões racionais, no sentido de que fazem o meIhor possível para sua sobrevivência e expansão frente aos concorrentes, ajustando meios a fins ou estratégias a objetivos, na tradição das teorias de administração. Todavia, mesmo sendo racionais no sentido apresentado, os agentes econômicos são limitados em sua capacidade cognitiva, uma vez que, numa economia monetária e permeada por inovações, impõese a necessi dade de tomar decisões cujos resultados não são conhecidos a priori. De modo mais genérico, há uma limitação cognitiva insanável vinculada à própria condição humana que torna o pleno conhecimento do presentee do futuro uma impossibilidade, não superada por procedimentos probabilísticos ou informacionais.

A questão não se reduz à insuficiência de informação sobre as variáveis presentes efuturas, considerando a multiplicidade de informações requeridas ( preferências dos consumidores, mercado de fatores, técnicas de produ- 
ção, comportamento dos concorrentes, variáveismacroeconômicas, etc.) ou ao caráter estocástico dos resultados esperados. Para esse tipo de questão, os modelos neoclássicos são bastante flexíveis, permitindo a incorporação do custo da obtenção da informação e estimativas probabilísticas nos cálculos econômicos, preservando o comportamento maximizador. A questão é mais complexa. Não se trata do fato de que as informações são múltiplas, difíceis e custosas; mas sim de que o conhecimento humano e empresarial envolvido na tomada de decisões é limitado, focalizado e parcial. Há uma limitação cognitiva que restringe a capacidade interpretativa e preditiva, mesmo que todas as informações fossem facilmente acessáveis a custo zero. A questão, em última análise, refere-se à capacidade limitada do discernimento humano, ainda mais num mundo em permanente transformação onde as decisões são privadas, interdependentes e condicionadas por um futuro desconhecido.

Em suma, há uma limitação em interpretar, selecionar, relacionar e hierarquizar os sinais fornecidos pelo ambiente. $N$ ão existe, de um lado, um conjunto bem delimitado - e comum a todos os agentes - do que se pode fazer e, de outro lado, regras de decisão racionais que independem da capacitação das empresas e instituições. 0 processo de decisão e de implementação constitui uma capacitação do agente tanto quanto seu domínio sobrea linha de produtos que possui.

Assim sendo, não há flexibilidade para viabilizar um comportamento maximizador, mas sim um leque de opções altamente restritivas. As instituições capitalistas são organizações sociais complexas, cujo comportamento se baseia em rotinas e regras de decisão socialmente construídas e somente alteradas por processos, normalmente dolorosos, de rupturas. Num mundo permeado por inovações e instituições construídas por um processo político e social complexo, o pleno conhecimento da realidade, a redução da incerteza a cál culos probabilísticos e a flexibilidade dos agentes são quimeras que não possuem qualquer base empírica.

Enquanto a noção de racionalidade limitada coloca as rotinas organizacionais como o contraponto da regra comportamental maximizadora, o tratamento da competição como um processo, no qual existem vencedores e perdedores econvivem agentes com tamanhos, margens de lucro e capacitações diferenciadas representa o contraponto da noção de equilí- brio. As atividades de busca e de seleção de inovações geram diversidade de forma intrínseca e supõem variedade entre os agentes e estratégias. Ao invés de uma ten dência inexorável a uma configuração de equilíbrio, em que a homogeneidade dos agentes prevalece, o sistema econômico passa a ser visto como em processo evolutivo, não havendo nenhum mecanismo necessário que suponha a ten dência ao equilíbrio. Processo competitivo, evolução e diversidade são a marca da análise da interação entre os agentes no mercado num contexto de inovações.

Segundo essa perspectiva, eincorporando conceitos de economia industrial (Possas, 1987), o mercado éo espaço concreto onde os capitais se defrontam, onde saem ganhadores e perdedores e onde uns apresentam um desempenho superior a outros. Assim, não é um espaço de "clones potenciais" que, sem estratégias al ternativas, maximizam igualmentee são igualmente eficientes. 0 mercado éo espaço da luta competitiva entre diferentes que perseguem incessantemente a criação de mais diferenças (via inovação), desencadeando processos reativos de busca de sua superação (via imitação). N ão há, assim, uma tendência produzida pelas forças da concorrência para a conformação de um estado de homogeneidade estrutural e comportamental entre os agentes. A competição constitui um processo de desequilíbrio no qual... not only the fittest but also the second, third, fourth... indeed a whole range of less fit will survive in the long run. The forces of economic selection working through the differential growth rates among firms with different unit costs is constantly ou twitted by the firms' imitation activities and intermittently disrupted by the firms' innovation activities (Iwai, in Dosi et al., 1990).

N essa perspectiva, o mercado não é visto apenas como uma instância al ocativa que vincula o comportamento individual maximizador com a tendência ao equilíbrio; mas sim, uma instância na qual os agentes, limitados em sua racionalidade e, portanto, em suas ações (relativamenterígidas), esforçam-se para criar diversidade e apresentam, como resultado, níveis diferenciad os de performance e de satisfação. É da luta entre agentes diversos que buscam a criação de desigualdades (ou assimetrias) que emergea evolução econômica, caracterizando um processo que está na raiz da transformação das estruturas e dos indicadores de performance. 
O mercado constitui, assim, um ambiente seletivo evolutivo no qual se definem os agentes vitoriosos e os perdedores, os que se expandem e aquel es que se contraem ou que são eliminados. Se todos os agentes possuem comportamentos predatórios e ineficientes, são estes mesmos agentes que definem 0 ambiente de seleção. Não dá para tomar como um postulado que o mercado atua de forma ótima a menos que haja falhas. 0 mercado é histórica e institucionalmente construído, definindo 0 padrão de eficiência dos agentes, como a área de saúde evidencia de modo exemplar. Seé assim, a questão da configuração institucional dos mercados em saúde deve se constituir numa preocupação permanenteda política pública, porque sua organização condiciona estratégias e resultados diferenciados.

Não obstante essas considerações, a análise tradicional desenvolve uma explicação plausível para o fato inelutável da existência de uma intervenção estatal abrangente em determinadas áreas, efetuando uma racionalização que permite justificar a ação pública, preservando suas hipóteses teóricas e sua visão do mercado competitivo como o espaço no qual se obtém a máxima eficiência econômica al ocativa, destacando-se o trabal ho de Arrow na área da saúde (1963, ed. 1971). O u seja, na medida em quea realidade social impõe a necessidade de intervenção, a análise neoclássica concebe o papel da ação governamental de forma compatível com sua visão de mercado, centrada na correção das falhas de mercado, expressas em termos das "assimetrias de informações", das "estruturas de mercado não competitivas", das "externalidades" edos "bens públicos". O problema é que faz isso sempre ten do como referência a restauração de uma situação ideal teórica - o mercado competitivo - totalmente descolada da realidade, o que acaba por levar a um tratamento no mínimo insuficiente do papel da intervenção estatal em áreas rel evantes e permeadas de inovações, interesses sociais e mecanismos de intervenção do Estado como a de saúde.

U m sistema econômico que se pauta pela busca, geração e apropriação de inovações, que geram rendimentos cumulativos para os agentes e para as economias nacionais (como já apontado desde Adam Smith, na análise da divisão do trabalho), sempre estará impregnado de assi metrias e de soluções ineficientes relativamente a outras soluções factíveis. Enfim, um sistema econômico sem externalidades, rendimentos crescentes, economias de escala, informação assimétrica, oligopólio, apropriação privada de rendas e - como uma síntese de todos esses elementos - inovações, não é capital ismo, uma vez que se abstraem os el ementos essenciais de sua evolução.

Como desdobramento, há uma total inversão da visão neoclássica de intervenção. A agenda rel evante não é a defensiva ( como resgatar o "paraíso perdido" do mercado competitivo), mas sim uma agenda ativa que assuma que as instituições, a diversidade, os poderes assi métricos de mercado, as interdependências, entre outras características, são constitutivas do capital ismo e não podem ser superadas de uma vez por todas (once and for all). No lugar das fal has de mercado, a preocupação que deve ser sublinhada éa das formas alternativas de sua organização, tendo como critério e referência o aproveitamento das oportunidades e o enfrentamento dos problemas trazi dos pela inovação e pel os processos de transformação.

Seguindo essa abordagem, o complexo industrial da saúdeé al go que deve ser analisado tanto na perspectiva defensiva tradicional, voltada para atenuar os impactos negativos dos interesses empresariais e das estratégias de inovação, quanto na sua dimensão econômica ativa de fonte de transformação e desenvolvimento. M uito mais do que atenuar falhas trata-se de construir um padrão de interação entre Estado e mercado que permita a constituição de um ambiente favorável para que o complexo da saúde se torne uma al avanca de inovação e desenvolvimento ao mesmo tempo em que esteja inserido no contexto dos objetivos da política nacional de saúde.

\section{Comentário final}

A área da saúde e o complexo industrial, que congrega os setores de atividade que dela fazem parte, aliam al to dinamismo industrial, elevado grau de inovação e interesse social marcante, sendo um campo central para a concepção de políticas industriais e tecnológicas articuladas com a política de saúde. A dicotomia entre uma visão sanitária do setor saú de e uma visão econômica não mais pode ser admitida porque tratar do segmento saúde significa, ao mesmo tempo, analisar um espaço de inovação e acumulação de capital, constituindo um subsistema impor- 
tante de geração de renda, emprego e desenvolvimento, e pensar as formas de organização institucional e regulação da atividade mercantil, de forma a viabilizar um padrão de estímulos e sanções que permitam a orientação dos setores em presariais da saúde para os objetivos de natureza social e para 0 atendimento das necessidades nacionais e da população. A ênfase em um dos pólos e a desconsi deração do outro se mostram uma opção analiticamente pobre e perigosa do ponto de vista normativo. Reconhecer a natureza capital ista da área da saúde, a produção em massa, a lógica empresarial e financeira e, sobretudo, a dinâmica das inovações é essencial para a concepção de políticas que almejem atenuar o descolamento inerente do sistema capitalista entre a busca do lucro e de mercados e 0 aten dimento às necessidades sociais e individuais. Não é desconsiderando ou negando a dinâmica capitalista que se poderá conceber políticas sociais adequadas. Ao contrário, somente pela compreensão de sua lógica de funcionamento é possível buscar meios eficazes para que finalidades sociais sejam atingidas nos marcos deste sistema.

N essa direção, procurou-se evidenciar que a política industrial e tecnológica é um problema da política de saúde, colocando-se o desenvolvimento do complexo da saúde como uma área crítica de intervenção. Para tanto, torna-se premente a integração dos grandes segmentos do complexo (produção de serviços e de bens industriais), numa perspectiva de que são, simultaneamente, espaços capital istas de acumulação, inovação e crescimento e de geração de bem- estar, incorporando interesses sociais legítimos não subordinados à lógica do mercado.

No campo analítico, a perspectiva centrada nas inovações aponta para a necessidade de uma abordagem teórica alternativa à convencional no campo da economia, centrada na dinâmica de transformação dos agentes, dos mercados e dos espaços nacionais, retomando uma visão de economia política que se concentra na mudança das estruturas e na rel ação, inerente ao capitalismo, entre Estado, economia e sociedade.

\section{Referências bibliográficas}

Albuquerque E \& Cassiolato J 2000. As especificidades do sistema de inovação do setor saúde: uma resenha da literatura como introdução a uma discussão sobre o caso brasileiro. Estudos F eSBE I. USP, São Paulo.

Arrow K 1971. Uncertainty and the welfare economics of medical care. In K Arrow. Essays in theory of riskbearing. $\mathrm{N}$ orth $\mathrm{H}$ oland, Amsterdã-Londres (trabalho escrito originalmente em 1963).

Boyer R 1988. Technical change and theory of "regulation". In G Dosi, C Freeman, R N elson, G Silverberg $\& L$ Soete. Technical change and economic theory. Pinter, Londres.

Braga JCS \& Silva PLBS 2001. Introdução. A mercantilização admissível e as políticas inadiáveis: estrutura e dinâmica do setor saúde no Brasil. In B N egri $\&$ G Giovanni. Brasil: radiografia da saúde. Instituto de Economia/Unicamp, Campinas.

Castells M 1999. A sociedade em rede. A era da informação: economia, sociedade e cultura. V 1. Paz eTerra, São Paulo.

Cordeiro H 1980. A indústria de saúde no Brasil. Graal, Rio de Janeiro.

Cordeiro H 2001. Descentralização, universalidade e eqüidade das reformas da saúde. Ciência $\&$ Saúde Coletiva 6(2):319-328.

Costa N R \& Barros Silva PL 2002. N otas sobre a característica do mercado de trabalho no setor saúde na década de 1990. (M imeo, em fase de publicação).

Costa N R, Ribeiro JM \& Barros Silva PL 2000. Reforma do Estado e mudança organizacional: um estudo dos hospitais públicos. Ciência $\&$ Saúde Coletiva 5(2): 427-442.

Dosi G, Freeman C, N el son R, Silverberg G \& Soete L 1988. Technical change and economic theory. Pinter, Londres.

Dosi G, Freeman C \& Fabrini S 1994. The process of economic development: introducting some stylize facts and theories on technologies, firms and institutions. Industrial and Corporate Change 3(1).

Erber FS 1992. D esenvolvimento industrial etecnológico na década de 90 - uma nova política para um novo padrão de desenvolvimento. Ensaios FEE 13(1):9-42.

Furtado AT \& Souza JHJ 2001. Evolução do setor de insumos e equipamentos médico-hospitalares, laboratoriais e odontológicos no Brasil: a década de 1990. In B N egri, \& G Giovanni. Brasil: radiografia da saúde. Instituto de Economia/U nicamp, Campinas.

Gadelha CAG 2002. Complexo da saúde. Relatório de pesquisa desenvolvido para o projeto Estudo de Competitividade por Cadeias Integradas, sob a coordenação de Coutinho LG, Laplane M F, Kupfer D \& Farina E. Núcleo de Economia Industrial e da Tecnologia do Instituto de Economia, convênio FE- 
CAM P/M DIC/ M CT/Finep.

Gadelha CAG, Quental C \& Fialho BC 2002. Saúde einovação: uma abordagem sistêmica das indústrias da saúde. Cadernos de Saúde Pública (em fase de publicação).

Gadelha CAG \& Temporão JG 1999. A indústria de vacinas no Brasil: desafios e perspectivas. BNDES, Rio deJaneiro.

Gelijns AC \& Rosemberg N 1995. The changing nature of medical technology development. In N Rosemberg, AC Gelijns \& H Dawkins. Sources of medical technology: universities and industry. National Academy Press, Washington, D.C.

Klevorick AK, Levin RC, N elson RR \& Winter SG 1995. On the sources and significance of interindustry differences in technological opportunities. Research Policy 24(1995):185-205.

Levcovitz E, Dias de Lima L \& M achado CV 2001. Política de saúde nos anos 90: relações intergovernamentais e o papel das $\mathrm{N}$ ormas O peracionais Básicas. Ciência \& Saúde Coletiva 6(2):269-291.

Lundvall B 1988. Innovation as an interactive process: from user-production interaction to the national system of innovation. In G Dosi et al. Technical change and economic theory. Pinter Publishers, Londres.

M agalhães LCG (coord.) et al. 2002. Evolução, tendências e características das importações e exportações de farmoquímicos e medicamentos: análise da balança de comércio exterior da indústria farmacêutica brasileira 1990-2000. N ota Técnica, Convênio M inistério da Saúde/IPEA/ AN PEC. Brasília.

M arx K 1983. 0 capital: crítica da economia política. Abril Cultural, São Paulo. (Coleção Os Economistas).

M inistério da Saúde 2000. A ções prioritárias na atenção básica em saúde. Brasília.
Negri B \& Giovanni G 2001. Brasil: radiografia da saúde. Instituto de Economia/U nicamp, Campinas.

Nelson RR \& Winter SG 1982. An evolutionary theory of economic change. $\mathrm{H}$ arvard U niversity Press, $\mathrm{Cam}$ bridge, $M$ ass.

N oronha JC \& Levcovitz E 1994. AIS-SUDS-SU S: os caminhos do direito à saúde. In $R$ Guimarães \& $R$ Tavares (orgs.). Saúde e sociedade no Brasil: anos 80. Abrasco-IM S-UERJ, Rio de Janeiro.

Pavitt K 1984. Sectoral pattern of technical change: toward a taxonomy and a theory. Research Policy 13(6).

Pierson P 1995. Dismantling the welfare state? Reagan, Tatcher, and the politics of retrenchment. Cambridge U niversity Press, N ova York.

Possas M L 1997. A cheia do "mainstream": comentários sobre os rumos da ciência econômica. Revista de Economia Contemporânea 1.

Queiroz S \& Gonzáles AJV 2001. M udanças recentes na estrutura produtiva da indústria farmacêutica. In B N egri \& G Giovanni. Brasil: radiografia da saúde. Instituto de Economia/U nicamp, Campinas.

Ribeiro JM, Costa NR \& Barros Silva PL 2001. Inovações na gestão descentralizada de redes e organizações hospitalares: os casos das regiões metropolitanas do Rio de Janeiro e de São Paulo. In B N egri \& G Giovanni. Brasil: radiografia da saúde. Instituto de Economia/Unicamp, Campinas.

Rosemberg N \& N elson RR 1994. American university and technical advance in industry. Research Policy 23: 323-348.

Schumpeter J 1985. Capitalismo, socialismo e democracia. Zahar, Rio de Janeiro.

Temporão JG 2002. Complexo industrial da saúde: público e privado na produção e consumo de vaci nas no Brasil. Tese de doutorado. IM S/UERJ, Rio de Janeiro.

Weber M 1993. Ciência e política: duas vocações. Cultrix, São Paulo.

Artigo apresentado em 20/10/2002

Aprovado em 12/12/2002

Versão final apresentada em 15/2/2003 